\section{Calculation of Tucker's three-mode common factor analysis}

\section{CONRAD W. SNYDER, JR., HENRY G. LAW, and PETER R. PAMMENT \\ University of Queensland \\ St. Lucia, Queensland 4067, Australia}

Three-mode common factor analysis, introduced by Tucker (1966), is applicable to two-facet repeatedmeasures data matrices. Carrier entities, usually persons, constitute one observational mode, and time or attributes, defined as distinct, fixed domains, constitute the other two observational modes. Some examples of appropriate data sets are: persons by trials by measures, persons by methods by measures, persons by items by situations, and so on. The three-mode analysis yields information pertaining to the dimensionality of common individual difference patterns, similar to classical factor analysis. Although evidently inspired by the classical factor-analytic model and sharing much of its conceptual fabric, the three-mode model explores data structure in a somewhat different fashion, as illustrated in Figure 1.

The fundamental equation of Tucker's (1966) model,

$$
R=\left(B^{*} C\right) G\left(A A^{\prime}\right) G^{\prime}\left(B^{\prime} * C^{\prime}\right),{ }^{1}
$$

where the factors among individuals are orthogonal, $\mathrm{AA}^{\prime}=\mathrm{I}$, designates that the reduced correlation matrix, $\mathrm{R}$, can be factored into three matrices: $\mathrm{B}, \mathrm{C}$, and $\mathrm{G}$. Whereas the classical factor analysis of a strung-out data matrix, $X \mathrm{ijk}$, would lead to a factor pattern of the combination variables, $F(J K \times m)$, Tucker's threemode common factor analysis exploits the inherent dimensionality of the observational data matrix and further analyzes the conventional factor results into two basic derivational modes, $\mathrm{B}(\mathrm{J} \times \mathrm{p})$ and $\mathrm{C}(\mathrm{K} \times \mathrm{q})$. The classical model factors $R$ as:

$$
\mathrm{R}=\mathrm{FF}^{\prime} \text {. }
$$

Tucker's three-mode common factor analysis breaks down $\mathrm{F}$ as:

$$
F=(B * C) G,
$$

where the derivational modes, $\mathrm{B}$ and $\mathrm{C}$, represent the idealized dimensions for the separate modes of the combination variables, and the interactional core, $\mathrm{G}(\mathrm{m} \times \mathrm{pq})$, describes the basic relations extant in the data matrix. The three-way core is dimensioned by the derivational modes $(\mathrm{m}<\mathrm{JK}, \mathrm{p}<\mathrm{J}$, and $\mathrm{q}<\mathrm{K})$, and its entries reflect the interactional processes underlying these idealized dimensions. In the classical model, the separate idealized modes are jumbled together in the combination variable analysis, and they are difficult to extricate. The core is assumed to be an identity matrix and is dropped from the system. In Tucker's three-mode model, the idealized modes and the core are explicit derivations of the structural model. The three-mode model provides a more directly relevant and intuitively interesting perspective of three-way classification data than that obtained from a traditional analysis of collapsed data.

In order to facilitate the use of Tucker's (1966) common factor model, three FORTRAN 10 programs (COLAPS, CORE, and ROTATE) have been written to interface with the readily available SPSS FACTOR routine (Nie, Hull, Jenkins, Steinbrenner, \& Bent, 1975) to calculate a three-mode solution. Operation assumes a DEC PDP-10 computer with an interactive terminal, but program alteration should be straightforward for other systems.

Calculation of the three-mode common factor analysis is achieved by the following six steps. (1) The data are arranged with $\mathrm{N}$ rows (persons) and JK columns (crossed attributes). The programs are dimensioned for

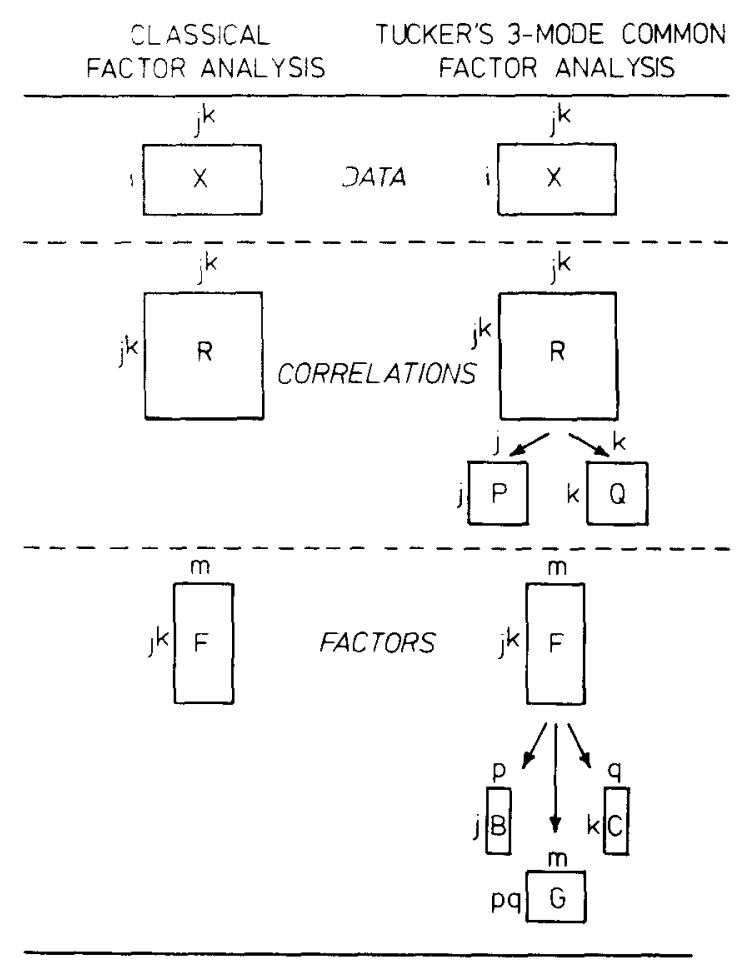

Figure 1. Comparison of classical factor analysis with Tucker's three-mode common factor analysis for the investigation of taxonomic structure in three-way designs. 
up to 120 combination variables, 10 factors each for $\mathbf{B}$ and $C$, and 40 factors for $F$.

(2) Using the SPSS FACTOR routine, the combination variable correlations are calculated and then factored as if carrying out classical factor analysis. Any of the factoring techniques can be used, depending on their appropriateness to the data set and relevance to the research question. PA2, principal factoring with iteration, appears to be the most popular choice. The correlation matrix, $\mathbf{R}$, the unrotated and rotated factor matrices, $F$, and the associated communalities and eigen values are obtained using OPTIONS $[5,6]$ and STATISTICS $[4,5,6]$. OPTIONS $[5,6]$ causes the correlation and unrotated factor matrices and the communalities to be written on an output file. STATISTICS [6] causes the transformation matrix to be printed. The print file should be retained, so that the transformation matrix can be extracted by a standard text editor. Also, the correlation and unrotated factor matrices and the communalities should be split into separate files by the editing facility available. Besides the output from the factor analysis of the strung-out data matrix, which is later useful for the interpretation of the core, four files are output for the additional steps: correlation matrix, unrotated factor matrix, communalities, and rotation transformation matrix.

Each file should be named with a unique code of five or fewer letters, followed by the [.DAT] extension. The accumulation of matrices is substantial as the threemode calculation proceeds. Files associated with these matrices have been retained separately in these programs in order to preserve flexibility and transportability. For convenience, the user may employ the conventional codes that are accepted as defaults in the interface programs:

$\begin{array}{ll}\text { CORR.DAT } & \text { R correlation matrix } \\ \text { FMAT.DAT } & \text { F unrotated factor matrix } \\ \text { FCOM.DAT } & \text { Communalities derived from R } \\ \text { FTRAN.DAT } & \text { F transformation matrix }\end{array}$

(3) The correlation matrix, $R$, is collapsed in to the $P$ and $Q$ matrices by an interface program called COLAPS. However, if a procedure other than PA2 is used, the appropriate input matrix for COLAPS may not be the correlation matrix. For example, if IMAGE is selected, then the image covariance matrix should be used. Program execution requires the order (number of variables) of $R, P$, and $Q$. The program also expects a communalities file (called FCOM.DAT) in (8F10.5) format and a parameter file (called PARAM.DAT), which specifies the levels of $P$ (first row) and $Q$ (second row) for each combination variable (identified by a 3012 format). For example, would indicate that there are three variables in $P$ and three variables in $Q$, and that the first variable in $R$ is the Cartesian product of the first variable of $P$ and the third variable of $Q$. If there are more than 30 combination variables, the program expects multiple lines for $P$ followed by the same number of lines for $Q$. Interaction with the program would proceed as follows:

\section{TOTAL N OF VARIABLES $=$}

$\mathrm{N}$ VARIABLES IN FIRST SUBMATRIX $(\mathrm{P})=$ $N$ VARIABLES IN SECOND SUBMATRIX $(Q)=$ INPUT FILE IS [DEFAULT $=$ CORR] =

Note-Although the files will have [.DAT] extensions, the extension should not be typed. It will be assumed by the FORTRAN operating system. Also note that a DEFAULT $=\langle\mathrm{CR}\rangle$.

OUTPUT ONE IS [DEFAULT $=$ PMAT $]=$

OUTPUT TWO IS [DEFAULT $=$ QMAT] $=$

\section{LAYOUT OF INPUT MATRIX (TYPE}

[DEFAULT=SPSS] or CORM) =

Note - CORM = upper triangular correlation matrix with $1 \mathrm{~s}$ on the diagonal and written in (10X, 7F10.4) format.

\section{LAYOUT OF OUTPUT MATRICES (TYPE}

[DEFAULT $=$ SPSS] OR CORM OR BOTH) $=$

PARAM FILE $[$ DEFAULT $=$ PARAM $]=$

PARAM FORMAT $[$ DEFAULT $=(3012)]=$

LAYOUT OF R MATRIX (TYPE "ROW” (STANDARD

SPSS OUTPUT) OR "PRINT" (EDITED) ) =

Note-The standard SPSS output arranges sequentially all the correlations with each variable into ( 8 F 10.7 ) rows; the print file output breaks the $\mathrm{R}$ matrix into 10 -column slices arranged in $(10 \mathrm{X}$, $10 \mathrm{~F} 12.6)$ rows. When editing the print file, delete all headers and blank lines.

DO YOU WISH TO INSERT COMMUNALITIES? (TYPE

"YES" OR "NO")

If yes...

COMMUNALITIES INPUT FILE (FORMAT $=(8 \mathrm{~F} 10.5))$

IS $[$ DEFAULT $=$ FCOM $]=$

(4) Both $P$ and $Q$ are factored, but PAl is used instead of PA2. The communalities, if required, are read off the diagonal elements of the COLAPS P and Q matrices and entered on the FACTOR line of the datadefinition control file using a DIAGONAL= statement. This is necessary because SPSS PA1 ignores the input diagonals. Again, the factor (B and C, correspondingly) and transformation matrices must be retained.

(5) The core, G, is calculated by an interface program called CORE. Program execution requires the unrotated $\mathrm{F}, \mathrm{B}$, and $\mathrm{C}$ matrices, the number of variables in each, the number of factors in each, their formats, and the combination variables parameter file, PARAM. Interaction with the program proceeds as follows: 
F MATRIX INPUT FILE IS [DEFAULT=FMAT ] = FORMAT FOR INPUT IS [DEFAULT $=($ SPSS $)=(8 \mathrm{~F} 10.70]=$ $\mathrm{N}$ VARIABLES IN $\mathrm{F}=$

N FACTORS IN F =

PARAM FILE IS [DEFAULT=PARAM] =

PARAM FORMAT IS [DEFAULT $=(3012)]=$

B MATRIX INPUT FILE IS [DEFAULT=BMAT] =

$C$ MATRIX INPUT FILE IS [DEFAULT $=\mathrm{CMAT}]=$

OUTPUT PRINT FILE IS [DEFAULT=GOUT] =

FORMAT FOR B MATRIX $[$ DEFAULT $=($ SPSS $)=(8 \mathrm{~F} \mathrm{10.7)}]=$

FORMAT FOR C MATRIX [DEFAULT $=($ SPSS $)=(8 \mathrm{~F} 10.7)]=$

$N$ VARIABLES IN $B=$

N FACTORS IN B $=$

$\mathrm{N}$ VARIABLES IN $\mathrm{C}=$

N FACTORS IN $\mathrm{C}=$

OUTPUT FILE FOR CORE MATRIX IS [DEFAULT=CORE] =

(6) The output from CORE is the input to another program called ROTATE, which counterrotates and transforms the core matrix. Program execution requires

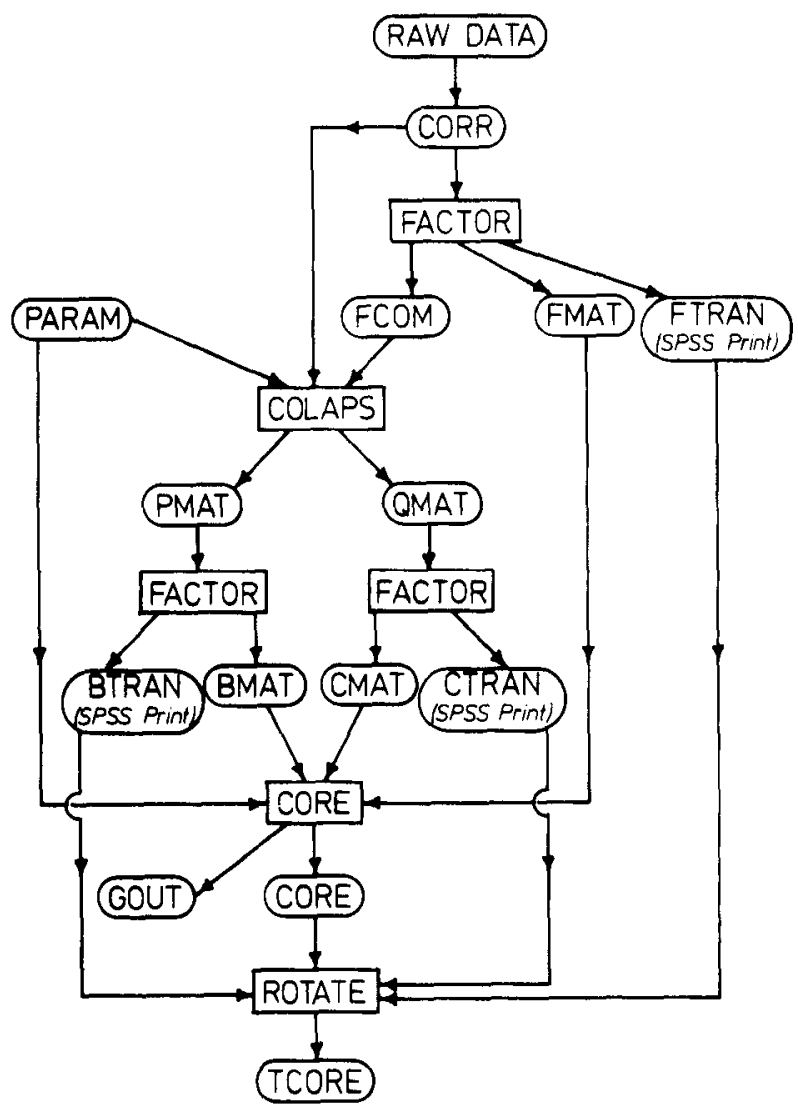

Figure 2. Calculational steps using the SPSS FACTOR routine for Tucker's three-mode common factor analysis. the transformation (rotation) matrices as well as the core, G. Interaction with the program proceeds as follows:

N FACTORS IN B $=$

INPUT FILE FOR B ROTATION [DEFAULT=BTRAN] =

FORMAT FOR BTRAN [DEFAULT $=($ SPSS $)=(10 \mathrm{X}, 10 \mathrm{~F} 12.6)]=$ N FACTORS IN C =

INPUT FILE FOR C ROTATION [DEFAULT=CTRAN] = FORMAT FOR CTRAN [DEFAULT $=($ SPSS $)=(10 \mathrm{X}, 10 \mathrm{~F} 12.6)]=$ N FACTORS IN F =

INPUT FILE FOR F ROTATION [DEFAULT=FTRAN] = FORMAT FOR FTRAN $[$ DEFAULT $=($ SPSS $)=(10 \mathrm{X}, 10 \mathrm{~F} 12.6)]=$ INPUT FILE FOR G (FORMAT $=(8 \mathrm{~F} 10.6))$

$[$ DEFAULT $=$ CORE] $=$ OUTPUT PRINT FILE [DEFAULT $=$ TCORE] =

Figure 2 summarizes the procedural steps for interface with SPSS PA2. Further technical details and conceptual explication of three-mode common factor analysis can be found in Snyder and Law (in press) and Tucker (1966, particularly pp. 301-311). Applications of the model are given in Firth and Snyder (in press), Leah, Law, and Snyder (in press), and Snyder (1976). SPSS interface programs are available at no cost by sending a blank magnetic tape and specifications to Henry G. Law, Department of Psychology, University of Queensland, St. Lucia, Queensland 4067, Australia.

\section{REFERENCES}

FirTh, P. M., \& SNYDeR, C. W., JR. Three-mode common factor analysis of self-reported difficulty in assertiveness. Australian Journal of Psychology in press.

Leah, J. A., Law, H. G., \& Snyder, C. W., JR. The structure of self-reported difficulty in assertiveness: An application of three-mode common factor analysis. Multivariate Behavioral Research, in press.

Nie, N. H., Hull, C. H., Jenkins, J. G., Steinbrenner, K., \& Bent, D. H. Statistical package for the social sciences (2nd ed.). New York: McGraw-Hill, 1975.

SNYDER, C. W., JR. Multivariate analysis of intrinsic individual differences in disjunctive conceptual behavior. Multivariate Behavioral Research, 1976, 11, 195-216.

SNYDER, C. W., JR., \& LAw, H. G. Three-mode common factor analysis: Procedure and computer programs. Multivariate Behavioral Research, in press.

Tucker, L. R. Some mathematical notes on three-mode factor analysis. Psychometrika, 1966, 31, 279-311.

\section{NOTE}

1. The asterisk (*) denotes the direct or Kronecker product. See Tucker (1966) for details.

(Accepted for publication July 11, 1979.) 